\title{
On Optimal Firewall Rule Ordering
}

\author{
El-Alfy, ESM; Selim, SZ \\ IEEE, 2007 IEEE/ACS INTERNATIONAL CONFERENCE ON COMPUTER SYSTEMS \\ AND \\ APPLICATIONS, VOLS 1 AND 2; pp: 819-824; Vol: \#\# \\ King Fahd University of Petroleum \& Minerals \\ http://www.kfupm.edu.sa
}

\begin{abstract}
Summary
In today's online connected world, almost all corporate networks use some form of perimeter firewalls to manage Internet connections and enforce a security policy at the corporate gateway. Although it can considerably enhance network security and protect business-critical information, a firewall with thousands of rules can become a bottleneck for network performance. The primary goal of this paper is to present a new rule order optimizer based on simulated annealing to find optimal configurations that minimize the average number of rule comparisons while preserving precedence relationships among disjoint rules. The proposed approach is evaluated and its effectiveness is compared with another approximate solution under several firewall configurations and policy profiles.
\end{abstract}

\section{References:}

1. ACHARYA S, 2006, IEEE INT C COMM ICC

2. ADAMIC L, 2002, GLOTTOMETRICS, P143

3. ALSHAER E, 2003, IFIP IEEE 8 INT S IN

4. ALSHAER E, 2005, IEEE J SEL AREA COMM, V23, P2069

5. ELALFY E, 2007, INT C ADV COMM TECHN

6. FULP E, 2005, 9 IFIP IEEE INT S IN

7. FULP EW, 2005, 10 IEEE INT S COMP C

8. GOUDA M, 2004, P 24 IEEE INT C DIST

9. HAMED H, 2006, ACM S INF COMP COMM, P332

10. KIRKPATRICK S, 1983, SCIENCE, V220, P671

11. QIU L, 2001, 9 INT C NETW PROT, P241

12. RANGANATH VP, 2003, IASTED INT C PAR DIS, P889

13. SUMAN B, 2006, J OPER RES SOC, V57, P1143

14. TARSA SJ, 2006, INT S COMP COMM ISCC, P755

(c) Copyright: King Fahd University of Petroleum \& Minerals; http://www.kfupm.edu.sa 
15. YU F, 2004, EFFICIENT MULTI MATC

16. YUAN L, 2006, IEEE S SEC PRIV

17. ZALENSKI R, 2002, IEEE POTENTIALS, V21, P24

For pre-prints please write to: abstracts@kfupm.edu.sa

(c) Copyright: King Fahd University of Petroleum \& Minerals;

http://www.kfupm.edu.sa 